\title{
MULTIPLANAR MRI AND CT IMAGING OF SELLAR AND PARASELLAR TUMOURS WITH CLINICAL AND PATHOLOGICAL CORRELATION
}

\author{
J. S. Aswini Jyothi', P. Ramya ${ }^{2}$, A. Suman Chandra ${ }^{3}$, M. Vijaya Kumari ${ }^{4}$ \\ ${ }^{1}$ Assistant Professor, Department of Radiology, Osmania Medical College/Hospital, Hyderabad. \\ ¿Senior Resident, Department of Radiology, Osmania Medical College/Hospital, Hyderabad. \\ ${ }^{3}$ Professor, Department of Radiology, Osmania Medical College/Hospital, Hyderabad. \\ ${ }^{4}$ Associate Professor, Department of Radiology, Osmania Medical College/Hospital, Hyderabad.
}

\section{ABSTRACT}

\section{AIMS AND OBJECTIVES}

- To review the anatomy of sellar and parasellar regions.

- To review a systematic anatomic approach to differential diagnosis of a sellar or parasellar tumors.

- To correlate the diagnosis on magnetic resonance imaging with pathological DIAGNOSIS.

\section{MATERIALS AND METHODS}

A Prospective study of a total of 40 consecutive patients who were referred to the department of Radiodiagnosis, Osmania General Hospital from December 2010 and September 2012 were included in the study after informed consent.

\section{RESULTS}

Majority of patients were between 20 to 40 years. Male preponderance was seen (Males 26, females 14). Commonest tumor encountered in our study was pituitary adenoma (65\%) among which macro adenomas constituted about $50 \%$ of the cases and $15 \%$ of cases were micro adenomas. Most of the functioning adenomas were seen in females - of which prolactinoma was the commonest.

\section{CONCLUSION}

MR imaging is preferred over CT for the diagnosis of pituitary adenomas because it provides multiplanar high contrast images, higher definition of small sellar lesions (Microadenomas) of the pituitary and further it improves anatomical definition of the pituitary, optic chiasma compression, cavernous sinus invasion before surgery. It is also preferred for postsurgical surveillance. CT has a complementary role in delineating bony destruction and the visualization of calcification and preoperative planning. Coronal images are the best for anatomical details of this region.

\section{KEYWORDS}

Multiplanar MRI, DWI, Computed Tomographic Imaging, Pituitary Microadenomas, Pituitary Macroadenomas, Sellar and Parasellar Meningiomas, Craniopharyngioma. Supraclinoid Aneurysm.

HOW TO CITE THIS ARTICLE: Jyothi JSA, Ramya P, Chandra AS, et al. Multiplanar MRI and CT imaging of sellar and parasellar tumours with clinical and pathological correlation. J. Evolution Med. Dent. Sci. 2016;5(19):969-977, DOI: 10.14260/jemds/2016/225

\section{INTRODUCTION}

Sellar and parasellar tumors are common clinical disorders accounting for 15 to $20 \%$ of all intracranial tumors among which pituitary adenoma stands high with 7 to $9 \%$ of all primary intracranial neoplasms. Radiological evaluation of sellar and parasellar tumors has progressed rapidly in recent years. Indirect methods of detecting sella and parasellar tumors on skull radiograph have been replaced by direct visualization with cross sectional imaging modalities. Sellar and parasellar areas are affected by various tumors, which add up to the morbidity and mortality in most cases. Thus a study designed to evaluate the contribution of imaging science towards diagnosis of sellar and parasellar tumors become relevant, since the radiological presentation can help to either rule out or confirm clinical suspicion. At times the radiology gives the diagnosis first in some unsuspected cases.

Financial or Other, Competing Interest: None.

Submission 20-01-2016, Peer Review 17-02-2016,

Acceptance 23-02-2016, Published 07-03-2016.

Corresponding Author:

Dr. J. S. Aswini Jyothi,

Flat: 204, Vasavi Bhuvana Apartments,

H: 8-3-981/1,3,4,6,8,10,11,

Srinagar Colony,

Hyderabad-500037,

Telangana.

E-mail: jyothijs@yahoo.com

DOI: $10.14260 /$ jemds $/ 2016 / 225$
Computed Tomography (CT) is the method of choice for initial evaluation of patients with potential suprasellar masses. Computed tomography (CT) was the first imaging modality to directly visualize the pituitary gland, hypothalamus, and optic chiasm. ${ }^{1}$ The bony structures in this region can be well evaluated with CT. It is more sensitive than either plain radiographs or magnetic resonance imaging (MRI) in the detection of calcifications within soft tissues. However, intravenous contrast agents frequently are necessary to improve the image contrast and to enhance the vasculature but CT involves radiation exposure. Today CT has proved completely reliable for detecting or ruling out the presence of a suprasellar mass, the direction and the degree of parasellar extension and the presence of any calcific or cystic components of the lesion. When multiple slice CT has been negative, further diagnostic studies have proved unrewarding. When CT has been positive, additional studies have been required in some cases to rule out aneurysm prior to craniotomy.

The multiplanar capabilities, high contrast resolution, lack of bone and surgical clip artifact and ability to demonstrate large arterial structures make Magnetic Resonance Imaging (MRI) a powerful tool in the preoperative, intra operative and postoperative assessment of sellar and parasellar tumors. Spin echo (SE) methods were the first to gain widespread popularity and continue to be the most 
widely used. Several groups have shown that short-repetitiontime, short-echo-time SE images (i.e., T1 weighted) generate very good contrast for visualizing pituitary pathology. 2,3,4,5,6 Compared with T1-weighted images, long-repetition-time, long-echo-time SE (i.e., T2 weighted) images have been less successful in demonstrating pituitary lesions, in particular, small adenomas.3,7 On the other hand, three-dimensional Fourier transform GE images have achieved greater success; these have been found to provide results comparable with T1-weighted SE methods.8,9

\section{MATERIALS AND METHODS}

A total of 40 consecutive patients who were referred to the department of Radiodiagnosis, Osmania General Hospital from December 2010 to September 2012 were included in the study after informed consent. The study group comprised 26 males and 14 females in the age group ranging from 6 yrs.-85 yrs. In all patients: complaints, history, clinical examination, other investigations and clinical diagnosis were obtained.

In all studies MR imaging was performed with a clinical $1.5 \mathrm{~T}$ system (General electrical medical systems). A Brain Coil was used.

\section{Sequences}

Axial, coronal and sagittal T2-weighted FSE with TR/TE $4800 / 80$ to 90 milli secs, Field of view $24 \times 24 \mathrm{~cm}$, Matrix size 512 x 512, slice thickness $3 \mathrm{~mm}$, inter slice gap $1.5 \mathrm{~mm}$, No. Of Excitations - 1 .

Axial T1 with TR /TE 540/16 millisecs, Field of view 24 x $24 \mathrm{~cm}$, Matrix 512 x 512 slice thickness $3 \mathrm{~mm}$, inter slice gap $1.5 \mathrm{~mm}$.

Spoiled gradient recalled TR/TE17-25/3-5, flip angle 35 degrees, FOV $22 \times 22 \mathrm{~cm}$, slice thickness $2 \mathrm{~mm}$. No inter slice gap, Matrix size 512 x 512. No. Of Excitations was one.

Dynamic Gd-enhanced MR imaging using T1 coronals, delayed sagittal and axials were taken. The time of imaging was kept identical.

DWI: Field of view $26 \mathrm{~cm}$, Slice thickness $5 \mathrm{~mm}$ with inter slice gap of $1.5 \mathrm{~mm}$, number of excitations $(\mathrm{NEX})=3$, matrix size 128×128, TR/TE 1000/81, B value 1000 .

A power-injector was used for the gadolinium injections (Omniscan, GE health care, $0.1 \mathrm{mmol} / \mathrm{kg}$ body wt.).

In all studies, CT imaging was performed with Asteion Toshiba single slice machine and for it the following parameters were used. Kilo Voltage $120 \mathrm{KV}$, Tube current 150 $\mathrm{mA}$ Axial and coronal thin sections of $3 \mathrm{~mm}$ slice thickness with no inter slice gap were taken, FOV $25 \mathrm{~cm}$, matrix $512 \mathrm{x}$ 512. Omnipaque contrast media was for contrast enhanced scans.

\section{IMAGE ANALYSIS}

In order to Analyze Sellar or Parasellar Tumors on MRI we used the following Anatomical Approach:

- First identify the pituitary gland and sella turcica.

- Then determine the epicenter of the lesion and whether it is in the sella or above, below or lateral to the sella.

- If it is in the sella, determine whether or not the sella is enlarged.

- Once the location of the mass is clear, analyze the signal intensity patterns: is the lesion cystic or solid?

- If solid, then looked for signal intensity of mass:

- T1w-hypointense/isointense/hyper intense
- $\quad \mathrm{T} 2 \mathrm{w}$-hypointense/isointense/hyper intense.

- Margins of mass: smooth /irregular/sharp.

- Dural attachment of the mass: wide based/narrow based.

- Flow voids, calcifications.

- Pituitary stalk.

- Chiasmatic involvement.

- Cavernous sinus involvement.

- Clival involvement.

- Degree of contrast enhancement: moderate/marked.

- Contrast enhancement pattern: homogenous/ heterogenous.

- Dural enhancement adjacent to the mass.

- Finally established a differential diagnosis.

Few patients were subjected to surgery and a detailed operative finding with their histopathology report was taken. The radiological diagnosis was correlated with clinical and histopathological diagnosis.

\section{OBSERVATIONS AND RESULTS}

Multiplanar magnetic resonance\& Computed Tomography imaging was done in 40 patients with clinical diagnosis of pituitary adenomas, suspicious of pituitary adenomas, intracranial space occupying lesions and correlated with histopathology.

Out of 40 cases, 26 were males and 14 were females. Age ranges include from 6 yrs. to 85 yrs. Most common tumour observed in the study was pituitary macroadenoma in 20 cases, followed by 8 cases of craniopharyngioma, then 6 cases of microadenoma and 5 cases of meningioma and one case was an aneurysm of supraclinoid ICA which was mistaken for meningioma on CT and later diagnosed to be aneurysm on MRI.

Out of 26 pituitary adenomas (20 macroadenomas, and 6 microadenomas) 6 of the macroadenomas and 3 microadenomas were functioning. The commonest of them was prolactinoma followed by ACTH secreting adenoma and growth hormone secreting adenomas. One case was of NELSON syndrome, another of mixed macro adenoma. These patients presented with endocrinopathy. Functioning adenomas were more commonly seen in females.

Microadenomas $>1 \mathrm{~cm}$ were confined to sella without extension into surrounding structures. Half of the micro adenomas were incidentalomas. Most of the macro adenomas were clinically diagnosed because they presented with visual disturbances. On MR imaging all microadenomas were hypointense on both T1WI and T2WI.

Macro adenomas $>1 \mathrm{~cm}$ were causing expansion of sella, almost all of them showed.

Suprasellar extension displacing and compressing the optic chiasma, 5 cases were showing "figure of 8" appearance and 8 cases with cavernous sinus invasion. Out of these 8 cases, 3 cases showed encasement of cavernous segment of ICA, 2 cases showed clival invasion, 2 cases showed sphenoid sinus invasion, 1 case showed encasement of both ACAs and ACOM which also showed peripheral rim of calcification. One case showed adjacent dural enhancement.

MR imaging of the macro adenomas showed that majority were homogenous and were hypointense to grey matter on both T1WI and T2WI. Cystic changes were seen in 6 
cases and haemorrhage with fluid - fluid levels was observed in 2 cases.

In all of the microadenomas, posterior pituitary bright spot was seen except for one case. In all cases of macro adenoma, posterior pituitary bright spot was not identified.

Out of all cases, 8 cases were craniopharyngiomas, age of whom was ranging from 6 yrs. to 33 yrs. Seven cases were in 6 to 14 yrs. and only one case was in age of 33 yrs. 7 cases showed solid cystic mass with calcifications in suprasellar cistern extending into sella, one case showed purely cystic lesion with rim and clumps of calcification. Solid components and the periphery of the cysts showed rim enhancement.

Out of 40 cases, 5 cases were meningiomas in the age group which ranged between 16 yrs. to 57 yrs. with broad base towards sphenoid. One case showed calcifications.

On contrast enhanced scans, one case of macroadenoma and two cases of meningiomas showed dural tail.

A case of aneurysm of Left Supraclinoid ICA was mistaken for parasellar meningiomas on CT later MRI was advised and it showed flow voids suggesting it as aneurysm.

4 cases of pituitary macro adenoma, 6 cases of craniopharyngioma, 3 cases of meningioma's were operated.

Histologically all cases of meningioma showed meningiotheliomatous pattern with cells wrapped in tight whorls with large nuclei and eosinophilic cytoplasm and all were Grade I according to the WHO classification. Pituitary adenomas showed the following findings: small round cells with monotonous uniform nuclei and eosinophilic cytoplasm.

Craniopharyngiomas showed adamantinomatous histopathology multistratified squamous epithelium with nuclear palisading and nodules of "wet" keratin.

\begin{tabular}{|c|c|c|}
\hline & Types of Lesions & No. of Cases \\
\hline 1 & Pituitary Adenoma & 26 \\
\hline 2 & Craniopharyngioma & 8 \\
\hline 3 & Meningioma & 5 \\
\hline 4 & Aneurysm & 1 \\
\hline \multicolumn{2}{|c|}{ Table 1: Types of Lesions } \\
\hline
\end{tabular}

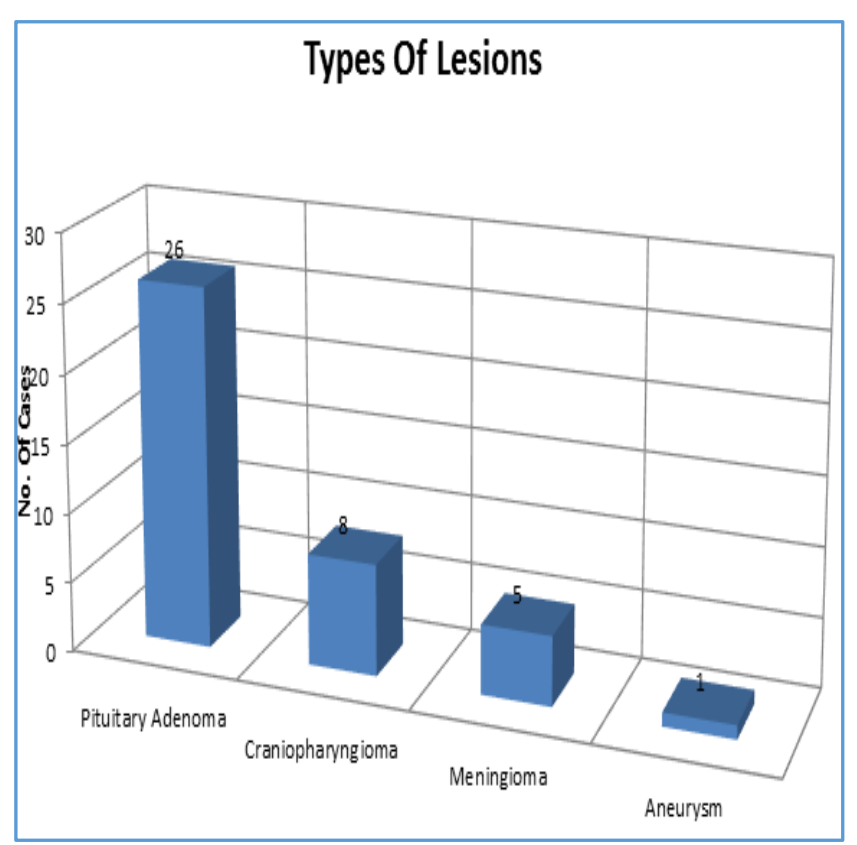

Chart 1a: Types of lesions

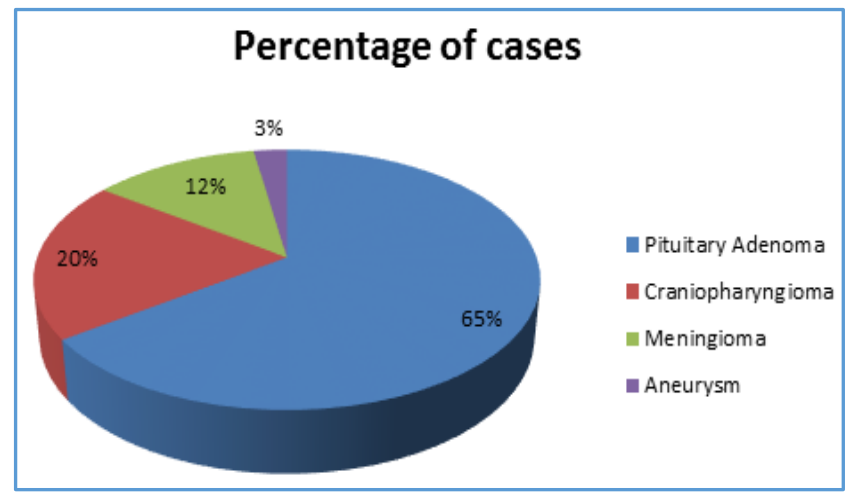

Chart 1b: Percentage of lesions

\begin{tabular}{|c|c|c|}
\hline & Sex & No. and Percentage of Cases \\
\hline 1 & Males & $26,65 \%$ \\
\hline 2 & Females & $14,35 \%$ \\
\hline \multicolumn{3}{|c|}{ Table 2: Sex distribution of Lesions } \\
\hline
\end{tabular}

\section{Sex Distribution Of Lesions}

- Males $n$ Females

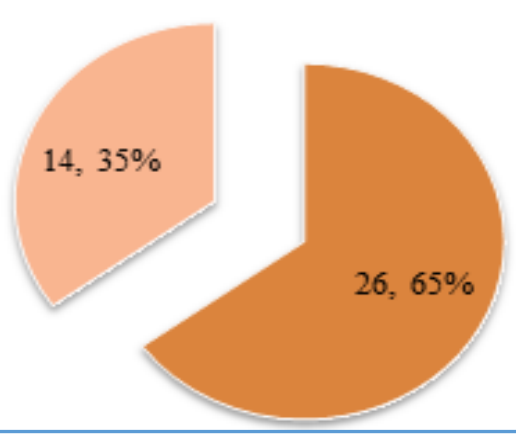

Chart 2: Sex distribution of Lesions

\begin{tabular}{|c|c|c|}
\hline & Location of Tumors & No. of Patients \\
\hline 1 & Mid Line & 34 \\
\hline 2 & 0ff Mid Line & 6 \\
\hline \multicolumn{2}{|c|}{ Table 3: Location of Tumors } \\
\hline
\end{tabular}

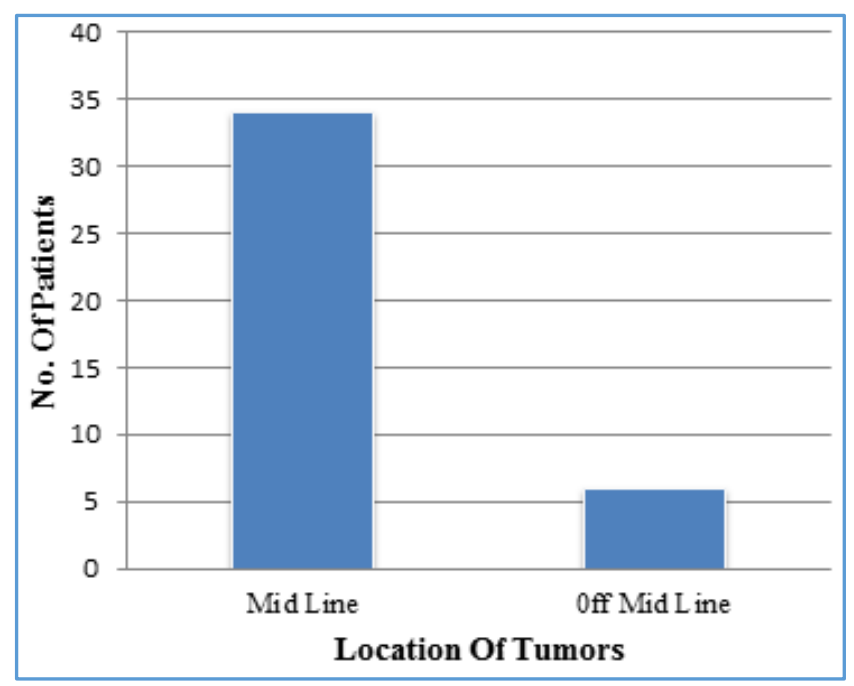

Chart 3: Location of Tumours 


\begin{tabular}{|c|c|c|}
\hline & Age Distribution & No. of Patients \\
\hline 1 & $1-10$ yrs. & 1 \\
\hline 2 & $11-20$ yrs. & 6 \\
\hline 3 & $21-30$ yrs. & 5 \\
\hline 4 & $31-40$ yrs. & 5 \\
\hline 5 & $41-50$ yrs. & 3 \\
\hline 6 & $51-60$ yrs. & 4 \\
\hline 7 & $61-70$ yrs. & 1 \\
\hline 8 & $71-80$ yrs. & 0 \\
\hline 9 & $81-90$ yrs. & 1 \\
\hline \multicolumn{2}{|c|}{ Table 4: Age distribution of Pituitary Adenomas(N=26) } \\
\hline
\end{tabular}

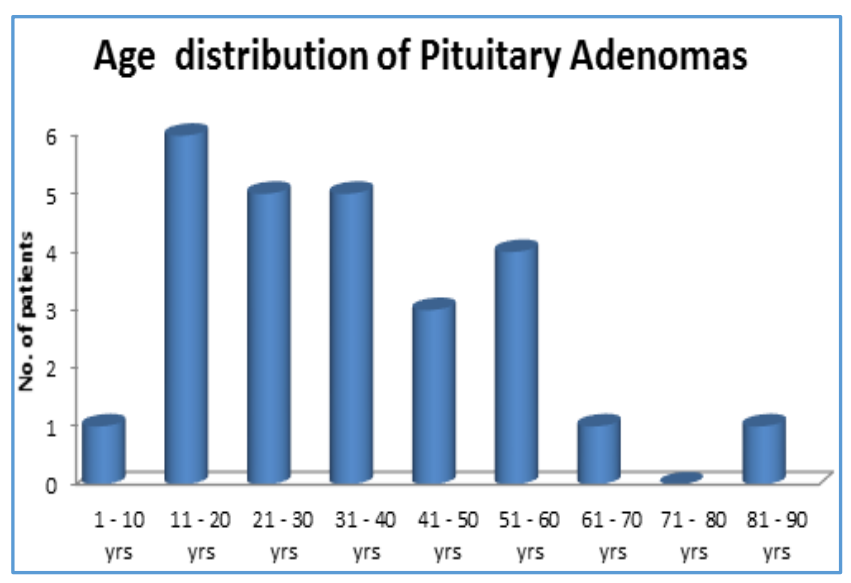

Chart 4: Age distribution of Pituitary Adenomas

\begin{tabular}{|l|c|c|}
\hline & Presentation & No. of Patients \\
\hline 1 & Head ache & 27 \\
\hline 2 & Visual Disturbances & 14 \\
\hline 3 & Endocrinopathy & 9 \\
\hline 4 & Raised Intracranial Tension & 7 \\
\hline 5 & Others & 2 \\
\hline \multicolumn{2}{|c|}{ Table 5: Presentation of patients } \\
\hline
\end{tabular}

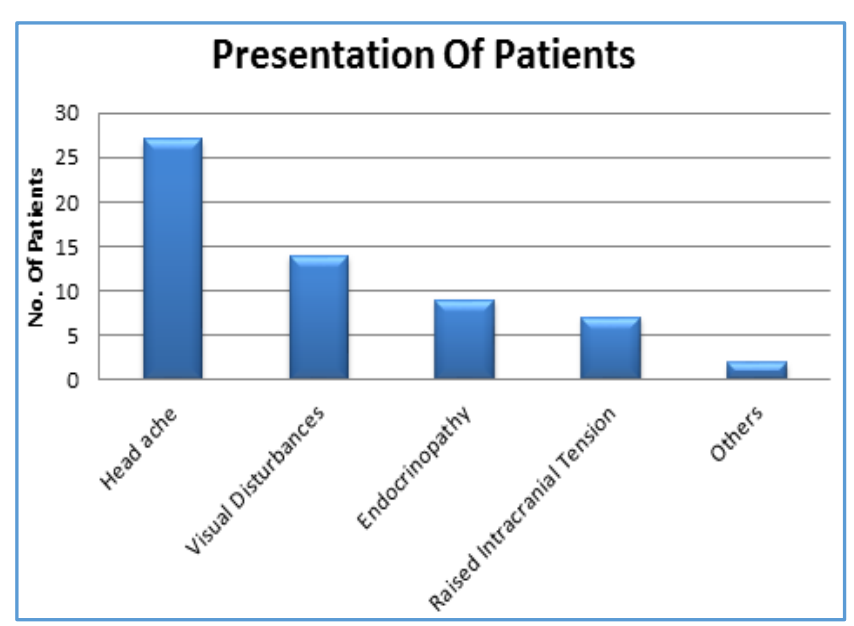

Chart 5: Presentation of patients

\begin{tabular}{|c|c|c|}
\hline & Type of Adenoma & No. of Patients \\
\hline 1 & Micro Adenoma & 6 \\
\hline 2 & Macro Adenoma & 20 \\
\hline \multicolumn{2}{|c|}{$\begin{array}{c}\text { Table 6: Types of Pituitary Adenomas based } \\
\text { on size (N=26) }\end{array}$} \\
\hline
\end{tabular}

\section{Size Of the Adenoma}

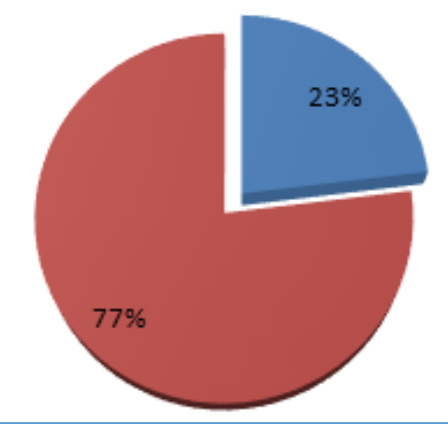

- Micro Adenoma

Macro Adenoma

Chart 6: Types of Pituitary Adenomas based on size

\begin{tabular}{|l|c|c|}
\hline & Type of Pituitary Adenomas & $\begin{array}{c}\text { No. of } \\
\text { Cases }\end{array}$ \\
\hline 1 & Functioning Adenoma & 9 \\
\hline 2 & Non Functioning Adenoma & 17 \\
\hline \multicolumn{3}{|c|}{ Table 7: Types of Pituitary Adenomas based on } \\
function. (N=26) \\
\hline
\end{tabular}

\section{Types of Adenoma based on function}

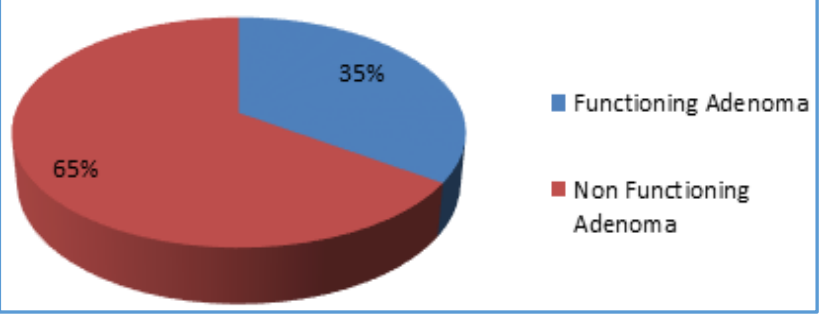

Chart 7: Types of Pituitary Adenomas based on function

\begin{tabular}{|c|c|c|}
\hline & Type of Functioning Adenoma & No. of Patients \\
\hline 1 & Prolactinoma & 4 \\
\hline 2 & ACTH Adenoma & 3 \\
\hline 3 & GH Adenoma & 1 \\
\hline 4 & Mixed & 1 \\
\hline \multicolumn{2}{|c|}{ Table 8: Type of Functioning Adenoma(N=9) } \\
\hline
\end{tabular}

\section{Types of Functioning Adenomas}

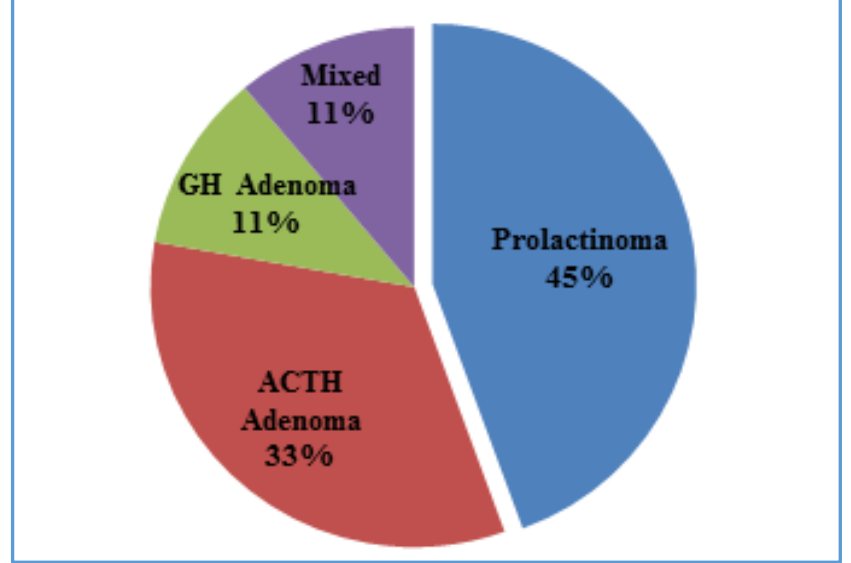

Chart 8: Type of Functioning Adenoma 


\section{DISCUSSION}

The sellar/parasellar and suprasellar regions are complex area and contain many important structures that can give origin to diversity of pathological lesions.

The study was done on 40 patients, of which contrast was given in 39. Sellar and parasellar tumours were analysed based on clinical findings, laboratory investigations, MR imaging and CT imaging. Patients with clinical diagnosis of pituitary adenomas, suspicious of pituitary adenomas, intracranial space occupying lesions were included in the study. Tissue diagnosis (Biopsy), surgery was done in feasible cases and tissue diagnosis was given in them.

In our study, the commonest tumours were pituitary adenomas with male predominance, to be specific macroadenomas constituted about $50 \%$ of the cases, $15 \%$ of cases were microadenomas and so all together constitute $65 \%$. $20 \%$ were craniopharyngiomas, $12 \%$ were meningiomas. Of all the sellar and parasellar tumours the percentage of pituitary adenoma as given in literature was $90 \% .{ }^{10}$ in our study it was only $65 \%$. Similar findings were seen in a study by Awatif A. ${ }^{11}$

Supraclinoid ICA aneurysm (3\%) which was mistaken for meningioma on computed tomography in our study, similar results were supported by two similar studies. ${ }^{12}$

The most common clinical presentation was headache (27 patients), next was visual disturbances (14 patients), endocrinopathy related ( 9 patients), raised intracranial pressure ( 7 Patients) other complaints ( 2 patients). Visual field defects were found in pituitary macroadenoma (13 patients), craniopharyngioma (0 patients) and meningioma ( 1 patient) findings are similar the study. ${ }^{13}$

Macroadenomas were the most common tumours on imaging studies and microadenomas were common in pathological studies (Autopsy).

The study showed that the majority of the pituitary adenomas were macroadenomas with extension to surrounding structures, among which commonest finding was suprasellar extension except in two cases in which adenoma was limited to sella only. Suprasellar extension of adenomas was causing displacement and compression of optic chiasma. 5 cases showed a "figure of 8" appearance. 8 cases were with cavernous sinus invasion. Out of these 8 , three cases showed encasement of cavernous segment of ICA, 2 cases showed clival invasion, 2 cases showed sphenoid sinus invasion, 1 case showed encasement of both ACAs and ACOM.

Among all cases, only 6 cases were microadenomas with pure sellar location.

Posterior pituitary bright spot could be seen in all the cases of microadenomas except for one case, but in macroadenoma it was not even seen in single case.

Optic chiasmatic displacement and compression was seen in macroadenomas and meningiomas.

It is important to have information on cavernous sinus extension and bony destruction in pituitary macroadenomas before surgery as cavernous sinus invasion leads to operative morbidity. Magnetic resonance (MR) imaging was superior to $\mathrm{CT}$ in detecting cavernous sinus invasion, tumour relation to ICA, optic chiasma and in internal characterization of the lesion.

Criteria followed in our study to describe cavernous sinus invasion were: asymmetry of cavernous sinuses, encasement of ICA $>45 \%$, presence of adenoma lateral to ICA, bulging of lateral wall of cavernous sinus. On CT it was difficult to say about cavernous sinus. In assessing cavernous sinus invasion coronal and axial sections were studied. Cavernous sinus invasion does not indicate aggressiveness of adenoma or invasiveness of adenoma; it is due to weakness of medial wall of cavernous sinus.

Coronal images are virtually always considered in conjunction with an imaging series in the sagittal plane, primarily for display of midline structures. Sagittal sequence helps in localization of the lesion in patients imaged for suspected pituitary pathology and coronal sequence helps in assessing the relation of adjacent structures to the lesion.

Coronal sections also help in assessment of suprasellar extension of the lesions. Sagittal images were used to localize the lesion. T2WI, DWI, ADC imaging help in the assessment of consistency of lesion. Soft lesions are hyper intense on T2WI, hard lesions were hypointense on T2WI, softer the lesion higher the ADC values. In our study 7 cases had hyper intense lesions, 2 cases had hypointense lesion while rest of them had isointense lesions.

The pulse sequence for best tissue contrast and anatomic display in this region is generally accepted to be T1-weighted imaging because characterization of components of lesion was easy on T1WI.

The peculiar vascularization of the adenohypophysis, supplied by a portal rather than an arterial circle, allows dynamic MR imaging. Using this technique, the normal gland enhances later than the pituitary stalk and cavernous sinuses. The tumours show delayed enhancement. Dynamic postcontrast imaging is thus a useful tool to increase the sensitivity of the exam especially in small microadenomas.

Prolactinoma was the common functioning adenoma in both macroadenomas ( 5 cases) and microadenoma (1 case). All prolactinomas were seen in females. Clival involvement was seen as altered signal intensity of clivus and was noted in two cases. Cystic changes and haemorrhage were observed in macroadenomas while microadenomas did not show any of these changes. As suprasellar extension was seen in all, most of them with macroadenomas had visual disturbances.

Homogenous enhancement, heterogenous enhancement, minimal enhancement were the types of enhancement observed in macroadenomas while all of the microadenomas showed homogenous enhancement. Sellar enlargement can be seen in both MR and CT, but erosion of sella and calcifications were better appreciated on CT. As our institution had a single slice CT, the resolution of MRI was excellent. But bony changes and calcifications still are better on CT. Out of 6 microadenomas- none was identified on CT.

The MR imaging is preferred over CT for the diagnosis of pituitary adenomas because it provides multiplanar high contrast images, higher definition of small sellar lesions of the pituitary and further it improves anatomical definition of the pituitary before surgery, it is also preferred for postsurgical surveillance. CT has a complementary role in delineating bony destruction and the visualization of calcification, preoperative planning. MR showed normal or abnormal blood vessels better than CT.

Sellar enlargement is typical but not exclusive of macroadenomas, it was seen in all cases of pituitary macroadenomas, 2 cases of craniopharyngiomas, Therefore, only the lack of sellar enlargement is helpful in diagnosis and 
pointing to a non-pituitary lesion, while sellar erosion is seen in macroadenomas only.

Contrast study was not required in few cases to diagnose pituitary adenomas. Dural tail was seen in one case of macroadenoma.

Meningiomas of the sellar/ parasellar region can arise from cavernous sinus, planum sphenoidale, diaphragma sellae, anterior clinoid processes, tuberculum sellae, medial lesser wing of sphenoid and optic nerve sheath. The majority of the cases i.e. 5 in number were $(12 \%$ of sellar and parasellar tumours) reported in the current study which were in parasellar location and were sphenoid meningiomas with meningiotheliomatous pattern and were extending into suprasellar location and into sella. All of them were grade I, by WHO classification system.

One case showed calcifications within. All cases of meningiomas showed homogenous enhancement. Classical features of meningioma like dural tail, was seen in two cases. Hyperostoses were not seen in any of the cases. In all these cases pituitary function was normal. Patients presented with headache and visual disturbances. Based on three features sellar and parasellar meningiomas can be differentiated epicenter of the lesion, homogenous enhancement, broad base towards dura. ${ }^{14}$

Craniopharyngiomas has no gender predominance but were with bimodal age distribution and with a peak incidence rate in children and adults between 5-14 and 50-74 years respectively. In our study, most cases are of paediatric age group $<14$ yrs.; only one case was a 33 yrs. old. In our study they account for $20 \%$ out of all sellar/parasellar lesions with adamantinomatous histological pattern and presented clinically with visual disturbance and increased intracranial pressure.

In the current study all the craniopharyngiomas were located in the suprasellar cistern extending into sella and parasellar areas. In craniopharyngiomas, better characterization of lesion was seen on MRI. All cases are solid and cystic with calcific foci, enhancement of the solid area of the lesion and periphery of the cyst was seen. Two cases showed recurrence within one year of duration.

\section{CASE NUMBER -1}

FINAL DIAGNOSIS: PITUITARY MICROADENOMA

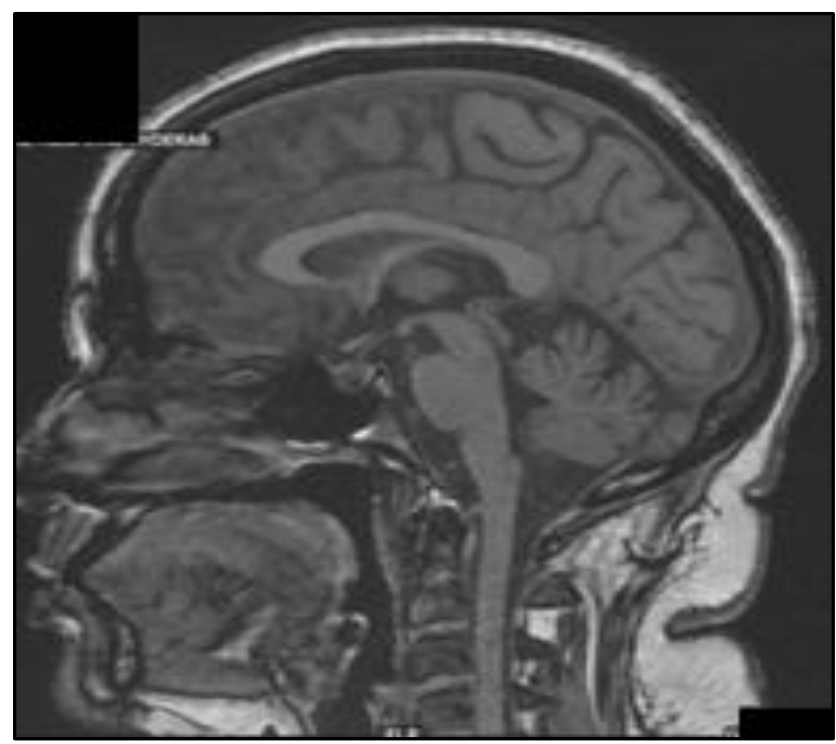

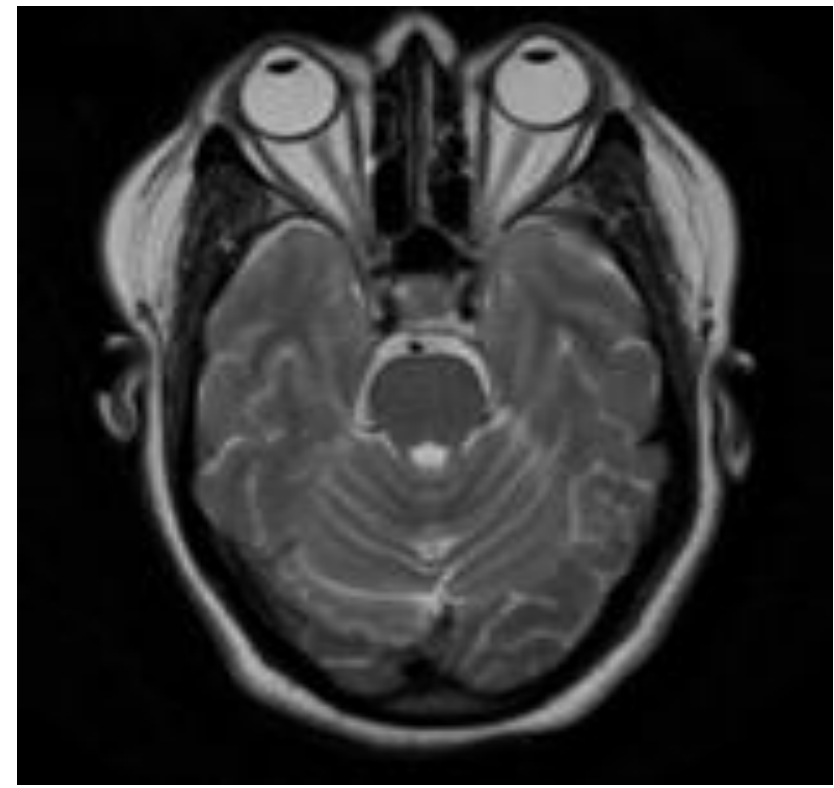

Sag T1, Axial T2 image shows hypointense lesion in sella
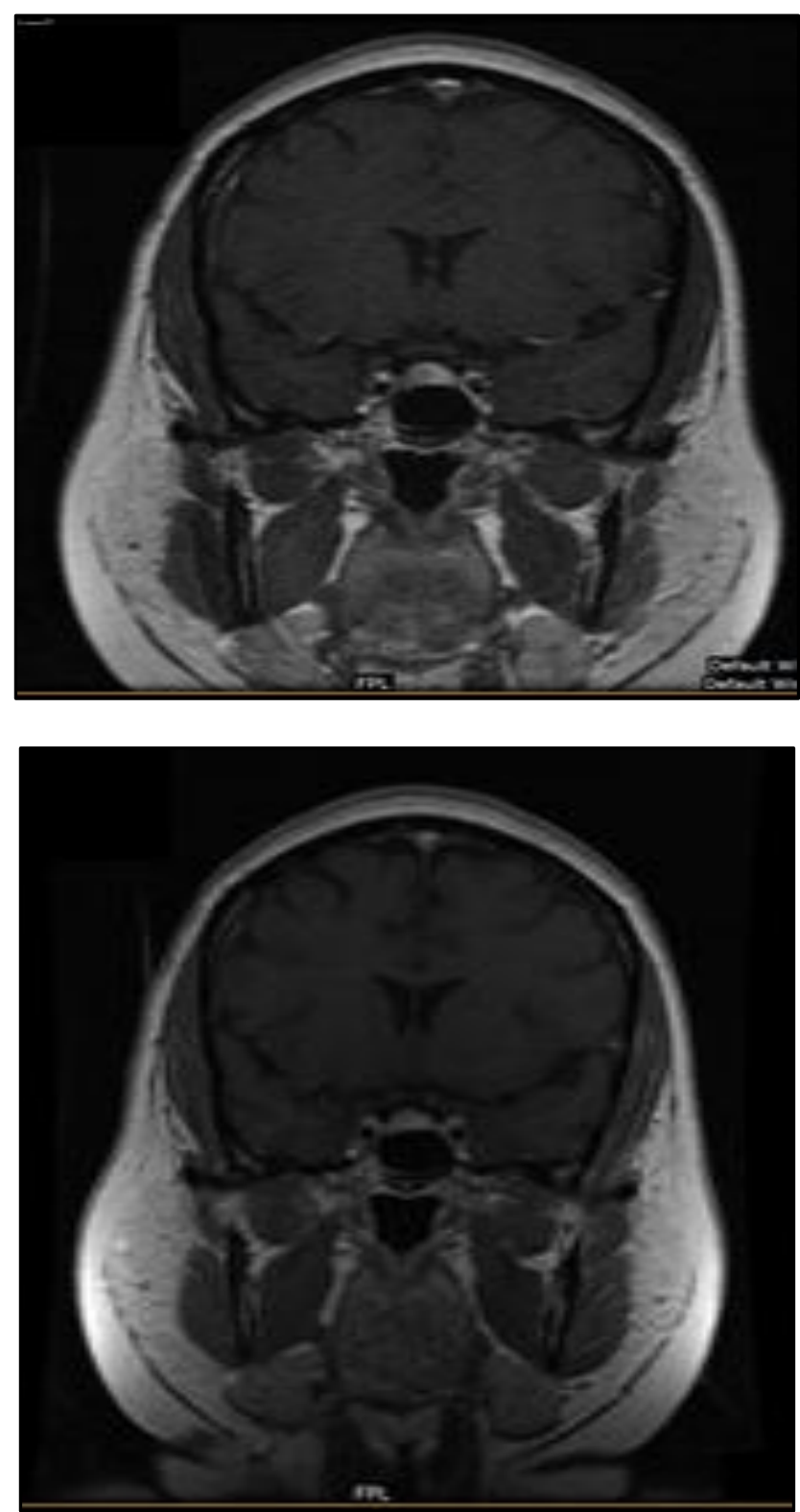

Coronal CEMR T1image shows homogenous enhancement of the lesion 


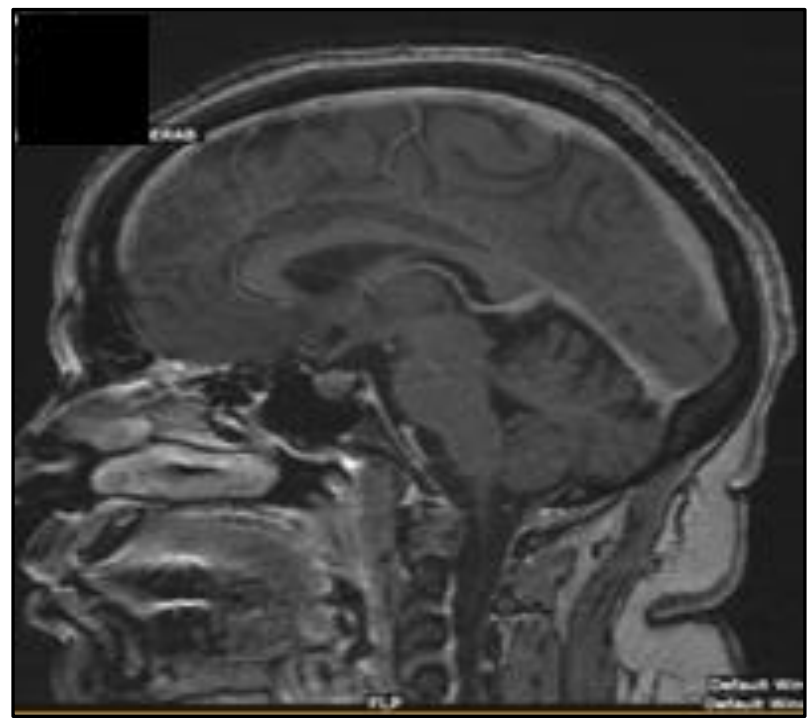

Sag CEMR T1 images show homogenous enhancement of the lesion

\section{CASE NUMBER - 2}

FINAL DIAGNOSIS $\quad$ : PITUITARY MACROADENOMA. SURGICAL DIAGNOSIS : PITUITARY MACROADENOMA. HISTOPATHOLOGICAL DIAGNOSIS: PITUITARY ADENOMA.
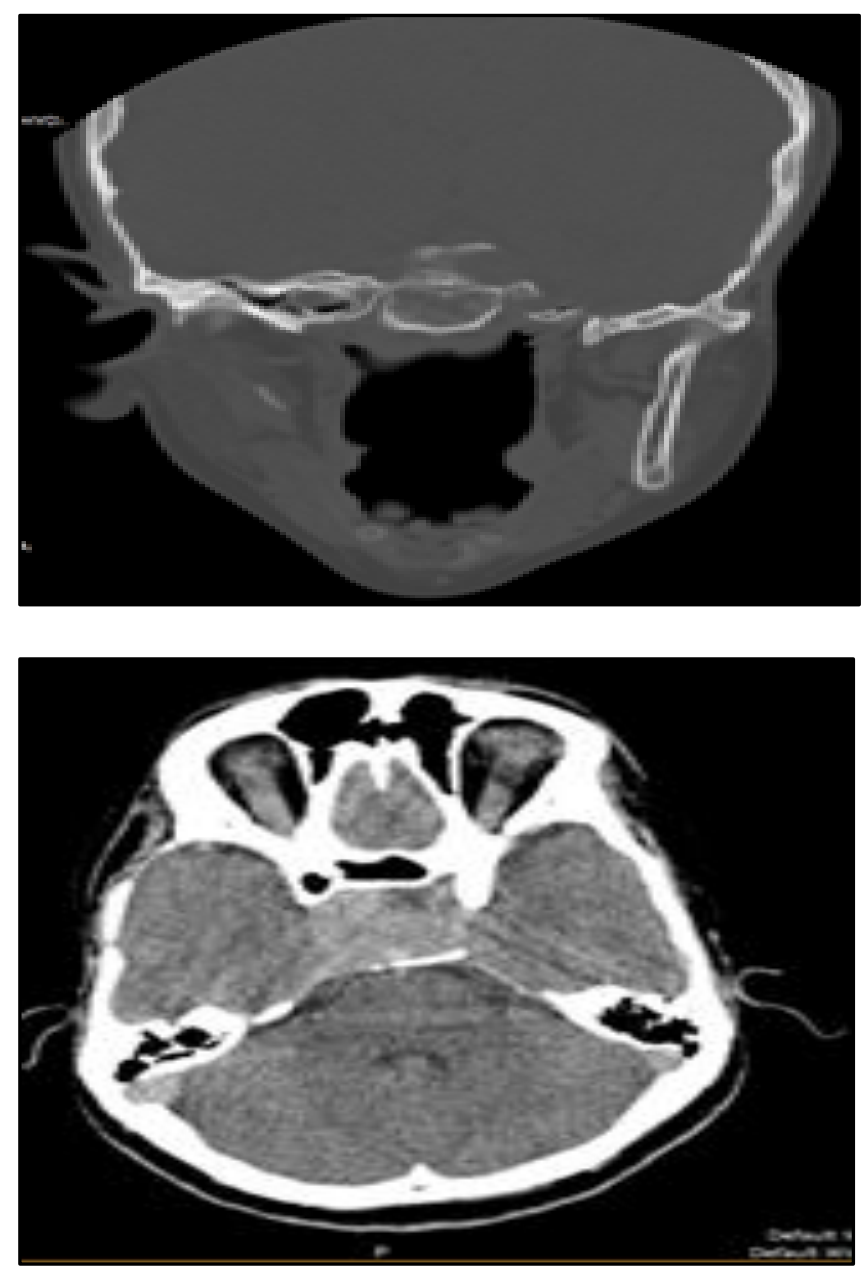

Coronal NECT bone window imaging showing sellar widening \& erosion and Axial NECT image Isodense lesion with cystic areas in sella.
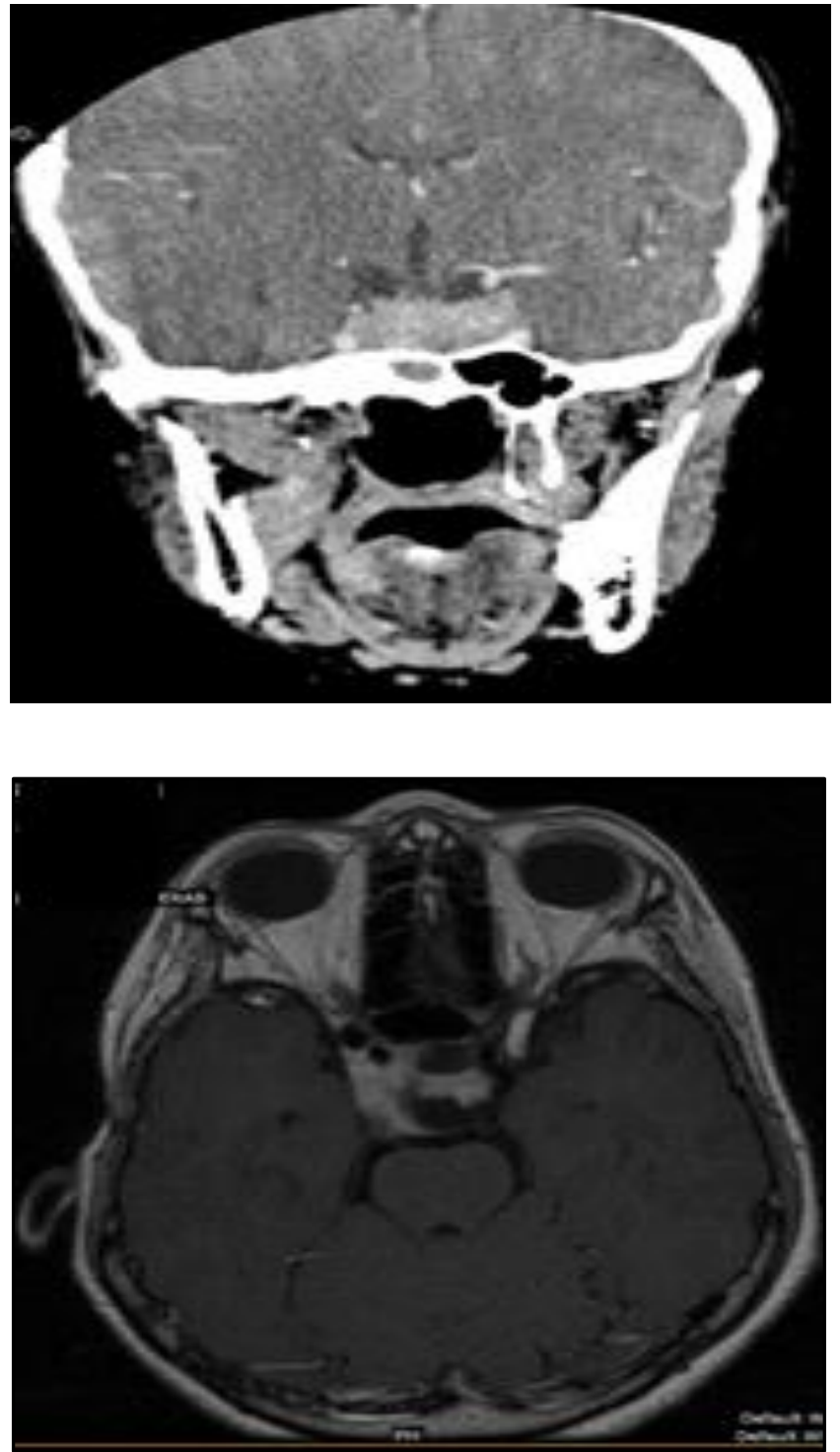

Coronal CECT image shows homogenous enhancement of the lesion and Axial CEMR T1 image showing homogenous enhancement of the lesion with cystic changes.

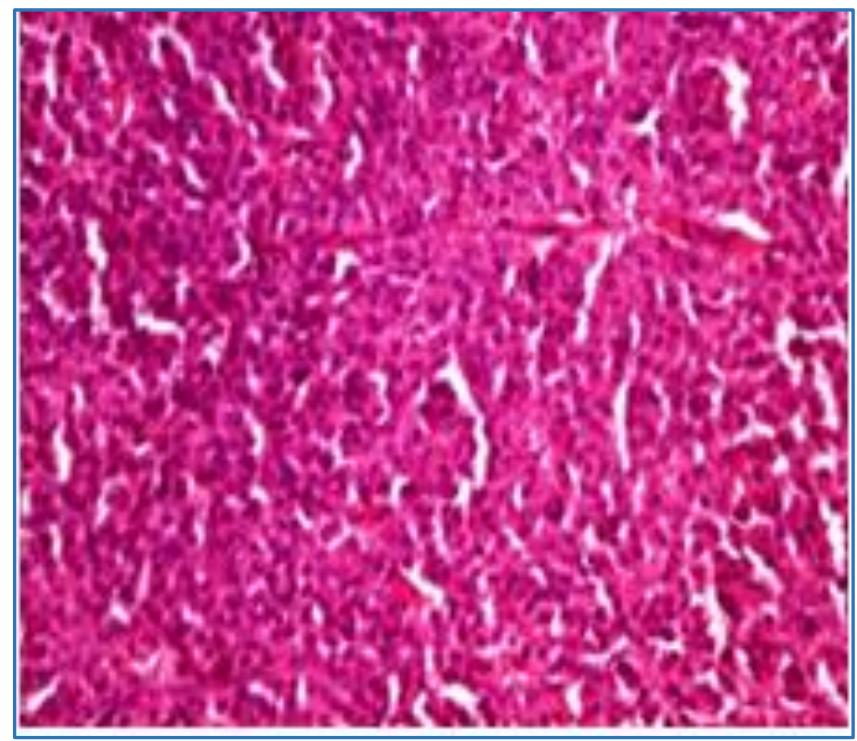

Histopathology image showing small round cells with monotonous nuclei and eosinophilic cytoplasm. 


\section{CASE NUMBER -3}

FINAL DIAGNOSIS: CRANIOPHARYNGIOMA.

SURGICAL DIAGNOSIS: MACHINE OIL LIKE MATERIAL SEEN INTRA OP. CRANIOPHARYNGIOMA

HISTOPATHOLOGY: ADAMANTINOMATOUS CRANIOPHARYNGIOMA.
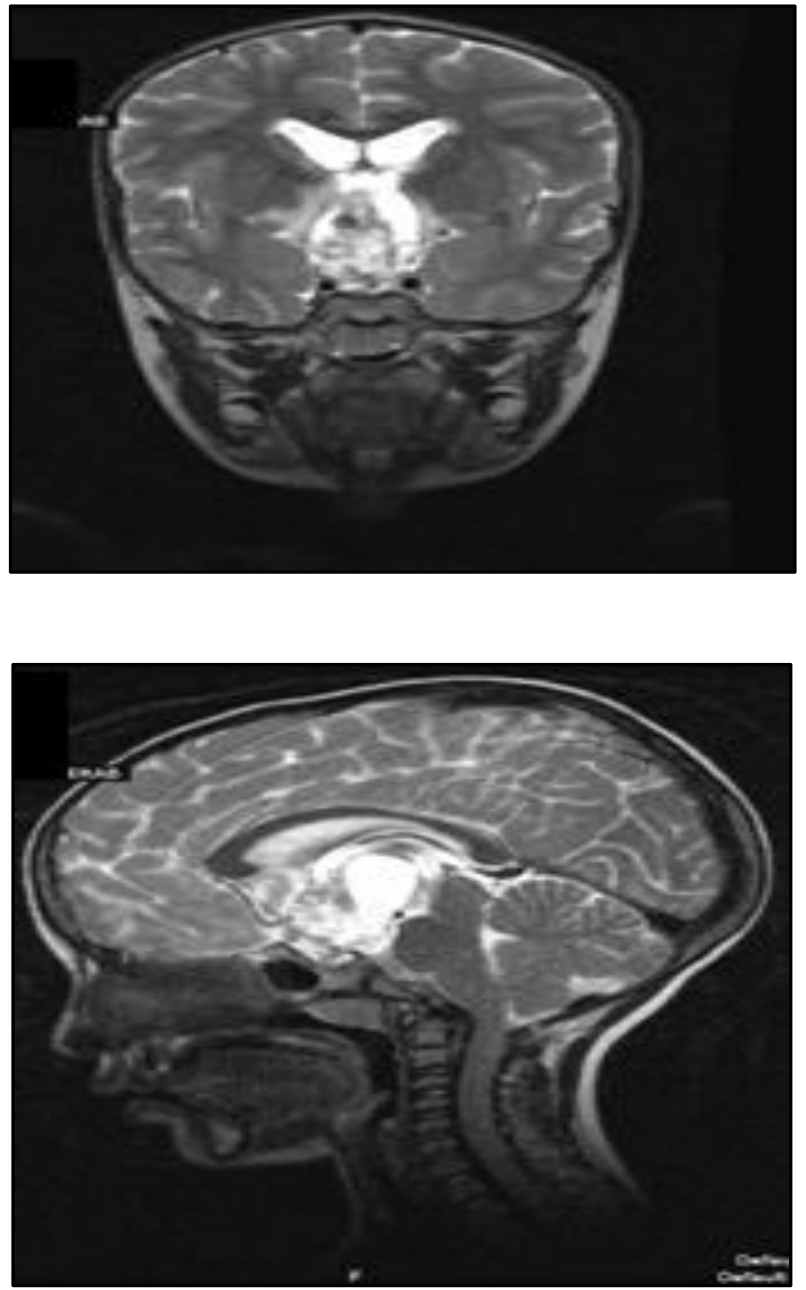

Coronal and Sag T2 images showing a hetergenously hyper intense lesion in suprasellar cistern.

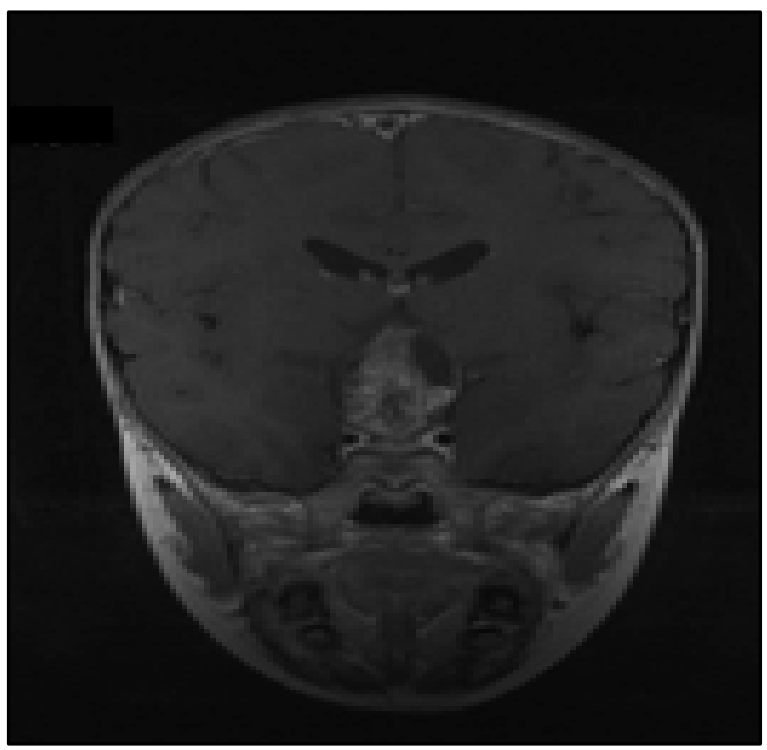

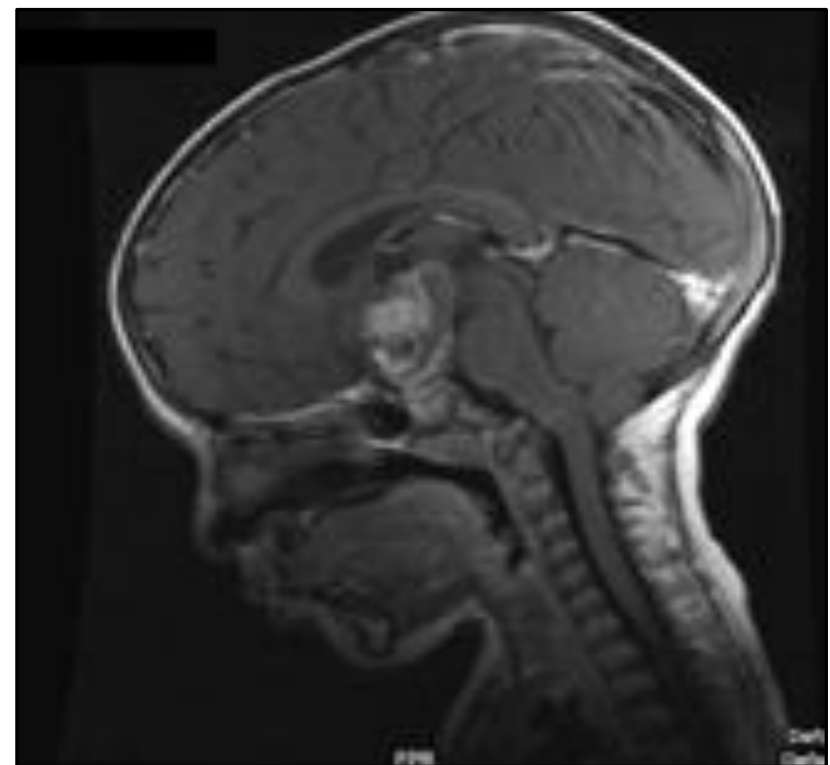

CEMR Coronal, Sag T1 images show heterogenous enhancement of the lesion.
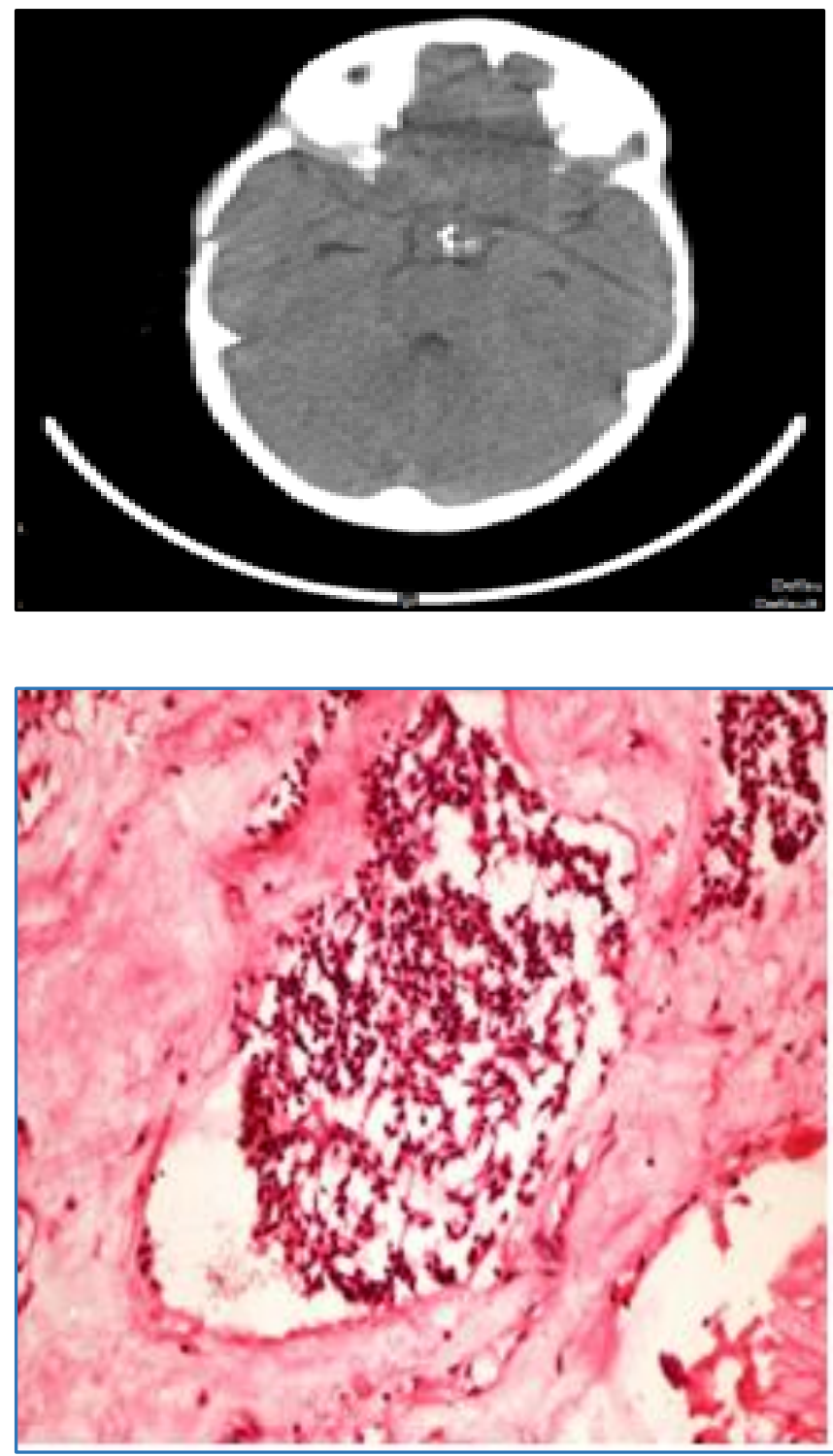

NECT show calcifications in the lesion. Histopathology shows-Multistratified squamous epithelium with nuclear palisading, nodules of "wet" keratin. 


\section{CONCLUSIONS}

The study was done on 40 patients but contrast was given in 39. Sellar and parasellar tumors were analysed based on clinical findings, laboratory investigations, MR imaging and CT imaging. Patients with clinical diagnosis of pituitary adenomas, suspicious of pituitary adenomas, intracranial space occupying lesions wereincluded in the study. Tissue diagnosis was given by performing biopsy or by surgery in feasible cases.

The age group ranged from 6 yrs. to 85 yrs., majority were between 20 to 40 years (25\%). Male preponderance was seen (Males 26, Females 14).

Systematic approach to the diagnosis of the lesion in sellar and parasellar area was: first to identify sella and pituitary gland, look for the epicenter of the lesion, broad base towards dura, signal intensity on T1WI \&T2WI, invasion of adjacent structures and enhancement pattern. By this approach we can come to a closer diagnosis.

Commonest tumor encountered in our study was pituitary adenoma (65\%). Macroadenomas constituted about $50 \%$ of the cases and $15 \%$ of cases were microadenomas.

Most of the functioning adenomas were seen in females and among these prolactinoma was the commonest.

Commonest extrasellar extension of pituitary macroadenoma was suprasellar, less common was infrasellar. Encasement of internal carotid artery $>50 \%$ was taken as reliable sign of cavernous sinus invasion.

MR imaging is preferred over CT for the diagnosis of pituitary adenomas because it provides multiplanar high contrast images, higher definition of small sellar lesions (Microadenomas) of the pituitary and further it improves anatomical definition of the pituitary, optic chiasma compression, cavernous sinus invasion before surgery. It is also preferred for postsurgical surveillance. CT has a complementary role in delineating bony destruction and the visualization of calcification and preoperative planning. Coronal images are best for anatomical details of this region. Dural tail sign is not specific for meningioma; it can also be seen in macroadenoma.

Craniopharyngiomas are more common in pediatric age group than elderly. Recurrence of craniopharyngiomas within a duration of year was seen in two cases.

In all operated cases, our diagnosis was correlating with histopathological diagnosis.

\section{REFERENCES}

1. Reich E, Zelch JV, Alfidi RJ, et al. Computed tomography in the detection of juxtasellar lesions. Radiology 1976;118(2):333-335.

2. Chakeres DW, Curtin A, Ford G. Magnetic resonance imaging of pituitary and parasellar abnormalities. Radiology Clinics North America 1989;27(2):265-281.

3. Kucharczyk W, Davis DO, Kelly WM, et al. Pituitary adenoma: high-resolution MRI at $1.5 \mathrm{~T}$. Radiology 1986;161(3):761-765.

4. Davis PC, Hoffman JC, Spencer T, et al. MR imaging of pituitary adenoma: CT, clinical, and surgical correlation. AJNR Am J Neuroradiol 1987;8:107-112.

5. Peck WW, Dillon WP, Norman D, et al. High-resolution MR imaging of pituitary microadenomas at $1.5 \mathrm{~T}$ : experience with Cushing disease. Am J Roentgenol 1989;152(1):145-151.

6. Pojunas KW, Daniels DL, Williams AL, et al. MR imaging of prolactin-secreting microadenomas. AJNR Am J Neuroradiol 1986; 7:209-213.

7. Kulkarni MV, Lee KF, McArdle CB, et al. 1.5-T MR imaging of pituitary microadenomas: technical considerations and CT correlation. AJNR Am J Neuroradiol 1988;9:5-11.

8. Rao VM, Vinitski S, Barbaria A, et al. Enhanced resolution of pituitary fossa with 3D fat suppressed gradient echo MRI: pre- and postgadolinium enhancement [Abstract]. AJNR Am J Neuroradiol 1989;10:892.

9. Stadnik T, Stevenaert A, Beckers A, et al. Pituitary microadenomas: diagnosis with two- and threedimensional MR imaging at $1.5 \mathrm{~T}$ before and after injection of gadolinium. Radiology 1990;176(2):419428.

10. Sautner D, Saeger W, Lüdecke DK. Tumors of the sellar region mimicking pituitary adenomas. Experimental and Clinical Endocrinology 1993;101(5):283-289.

11. Awatif A Jamal, Rana A. Ajabnoor sellar and parasellar lesions: a 15 years university hospital experience, Saudi Arabia. Journal of American Science 2012;8(5):74-82.

12. Lee BC, Deck MD. Sellar and juxtasellar lesion detection with MR. Radiology 1985;157(1):143-7.

13. Fu X, Wang H. Ocular symptoms of tumors at sella turcica region. Yan Ke Xue Bao 1996;12(3):166-8.

14. Taylor SL, Barakos JA, Harsh GR, et al. Magnetic resonance imaging of tuberculum sellae meningiomas: preventing preoperative misdiagnosis as pituitary macroadenoma. Neurosurgery 1992;31(4):621-627. 